\title{
T CORRESPONDENCE
}

\section{Positional Skull Deformities}

\author{
Etiology, Prevention, Diagnosis, and Treatment
}

by PD Dr. med. Dr. med. dent. Christian Linz, Dr. med. dent. Felix Kunz, Dr. med. Dr. med. dent. Hartmut Böhm, and PD Dr. med. Tilmann Schweitzer

in issue $31-32 / 2017$

\section{The Cause is Cesarean Section}

The fact that our children sleep on their backs certainly does not to lead to skull deformities; if it did, all children of my generation (1951) would be walking around with flat heads, as we lay on our backs until we could roll over independently.

Even the youngest healthy children turn their heads in all directions, reducing pressure on specific parts of the skull that might lead to lasting distortion. Distortions of the skull are caused by reduced or disordered function of the cranial sutures, resulting in uneven muscle tension and disruption to the craniosacral system. This can be treated very successfully with manual therapy.

KISS (kinetic imbalances due to suboccipital strain) syndrome is also often present in such cases. This is an abnormal position of the head, sometimes detectable even by laypeople as being "lopsided." Babies who suffer from this can be recognized by the fact that the neck, in particular, appears twisted and the body is stretched backwards. As a result of reduced mobility and uneven muscle tension on the still malleable bones of the skull, the head is often distorted and the hair rubbed thin. There is frequently an associated neurophysiological disorder, which can lead to sleep disorders, long periods of crying, and digestive problems (known as 3-month colic).

Interestingly, skull deformities are increasing to the same extent that cesarean sections are replacing normal deliveries. Unnatural delivery, including cesarean section, is a leading factor in the development of skull deformities.

However, long-term consequences can usually be prevented by prompt diagnosis and targeted manual therapy, which restores the balance of the cervical vertebrae and the bones of the skull (which always remain mobile until old age) (2). DOl: 10.3238/arztebl.2018.0038b

\section{References}

1. Linz C, Kunz F, Böhm H, Schweitzer T: Positional skull deformities-etiology, prevention, diagnosis, and treatment. Dtsch Arztebl Int 2017; 114: 535-42.

2. Biedermann H: Das KISS-Syndrom der Neugeborenen und Kleinkinder. Manuelle Medizin 1993; 31: 97-107.

\section{Dr. med. Gerhard Otto}

Physician specializing in general practice, chiropractic, natural remedies, and acupuncture

Germany

info@privatpraxis-essen.com such as helmet therapy, are featured in publications, whereas unspectacular prevention measures such as positioning and handling are not reflected in the literature. DOI: 10.3238/arztebl.2018.0038a

\section{References}

1. Linz C, Kunz F, Böhm H, Schweitzer T: Positional skul deformities-etiology, prevention, diagnosis, and treatment. Dtsch Arztebl Int 2017; 114: 535-42. 
synapse strength of synaptogenesis are very closely dependent on the motor skills of the growing child (which are initially purely reflexive), particularly in the first 3 to 4 months of life. For optical control (development of head control) especially, these correlations are not merely plausible but have been well researched for many years.

Spatial orientation, which matures as a result, is vital to the development of both perceptual systems and language (2).

Sensory and cognitive limitations in child development associated with skull asymmetry (with limited range of motion of the head) are not only plausible but have been well demonstrated up to school age (3).

Regarding treatment: if, as is usually the case, there is an underlying functional disorder of the head-neck transition, for example following a birth trauma, early functional treatment using manual and osteopathic medicine in this region is reliably successful. Arlen's atlas therapy and osteopathic manipulation provide physician-directed treatment options, that-in my personal experience-are superior to standard physiotherapy or at least are a useful complement to these.

The success of osteopathy in children with asymmetric posture has been demonstrated by external evidence (4). These procedures often eliminate the need for skull orthosis and should therefore be mentioned in the article. DOI: $10.3238 / a r z t e b l .2018 .0038 \mathrm{c}$

\section{References}

1. Linz C, Kunz F, Böhm H, Schweitzer T: Positional skull deformities-etiology, prevention, diagnosis, and treatment. Dtsch Arztebl Int 2017; 114: 535-42.

2. Coenen W: Manuelle Medizin bei Säuglingen und Kindern. Berlin Heidelberg: Springer Verlag 2016: 6-7.

3. Miller R, Clarren S: Long-term developmental outcomes in patients with deformational plagiocephaly. Pediatrics 2000; 105: e26.

4. Philippi H: Osteopathie in der Pädiatrie: Wirkprinzip und Indikation. Kinderärztliche Praxis 2008; 79: 290-5.

\section{Dr. med. Matthias Riede}

Deutsche Gesellschaft für Osteopathische Medizin

ÄMKA e. V., Ärztegemeinschaft für Manuelle Kinderbehandlung und

Atlastherapie

Freiburg im Breisgau

Germany

m.riedel@posteo.de

\section{Caused by Spinal Block}

As a pediatrician, I regularly see infants with skull deformities.

One cause of the skull deformities described which the article does not mention is vertebral blockages caused by birth traumas, for example in the atlas, thoracic spine, or iliosacral regions (1).

In addition to the skull deformities described, these can become clinically manifest in the form of scoliosis of the torso, pelvic obliquity, limited range of motion of the head, latching difficulties, and bouts of screaming caused by pain.

Treatment by an osteopath who specializes in infants can, in my experience, swiftly resolve the cause and re- lated complaints by correcting such blockages and spares children months of physiotherapy or helmet therapy.

DOI: 10.3238/arztebl.2018.0039a

\section{References}

1. Linz C, Kunz F, Böhm H, Schweitzer T: Positional skull deformities -etiology, prevention, diagnosis, and treatment. Dtsch Arztebl Int 2017; 114: 535-42.

Ramona Höne

Pediatrician

Hamburg

Germany

ulrichhoene@alice-dsı.de

\section{In Reply:}

Thank you for the constructive feedback on our review article Positional Skull Deformities, which we are glad to address (1).

The relationship between the entirely sensible recommendation for infants to be always placed on their backs to reduce the risk of sudden infant death syndrome and the development of positional skull deformities has been confirmed (2). As stated, one of the possible causes is limited movement, sometimes related to birth traumas. Kinetic imbalances due to suboccipital strain (KISS syndrome) are not seen as a defined disease pattern by the German Society for Pediatric Neurology (Deutsche Gesellschaft für Neuropädiatrie) (3). Deutsches Ärzteblatt requests authors to base articles such as ours on existing, evidence-based recommendations. As described in the article, limited range of motion of the head is often the cause of positioning plagiocephaly and should therefore be treated promptly. Such treatment may include physiotherapy or manual therapy, for example. As quoted in current US guidelines, we have included this point under the heading of physiotherapy (4) - the term "osteopathy" is not used. When range of motion of the head is limited, we recommend prompt physiotherapy, manual therapy, or osteopathy to the parents of our patients. As stated, stage-appropriate treatment should be selected; helmet therapy is usually the treatment option of last resort. Because a cranial orthosis that molds the skull does not treat the cause of limited range of motion of the head, we believe it is important to continue with physiotherapy, manual therapy, or osteopathy in parallel to helmet therapy. The explicit advice is not to use mobile positioning aids such as rings or cushions, due to the risk of sudden infant death (2).

The issue of development delays in affected children is certainly a fascinating and highly controversial subject. As Dr. Riedel rightly states, there are studies that indicate a correlation. Unfortunately, none of the available studies addresses the question of cause and effect: was there first a developmental delay which resulted in a positional skull asymmetry, or does a positional skull deformity lead to developmental delays? In addition, the case numbers investigated are small, and only some studies are controlled. Our own recent research, in which we investigated early language development in 
affected children and children in a control group, found no differences between the two groups $(5,6)$. These findings are in line with our clinical impression. However, the question of neurocognitive effects of positional skull deformities can certainly not yet be answered conclusively, and further studies on this are needed.

In discussing the cause, effects, and treatment of positional skull deformities it is important to maintain the recommendation to place infants on their backs and to educate parents promptly and comprehensively. Worries or lack of awareness concerning the development of skull deformities should under no circumstances lead to this sensible recommendation being rejected. DOI: $10.3238 / a r z t e b l .2018 .0039 b$

\section{References}

1. Linz C, Kunz F, Böhm H, Schweitzer T: Positional skull deformities-etiology, prevention, diagnosis, and treatment. Dtsch Arztebl Int 2017; 114: 535-42.

2. AAP Task Force on Sudden Infant Death Syndrom: SIDS and other sleep-related infant deaths: evidence base for 2016 updated recommendations for a safe infant sleeping environment. Pediatrics 2016; 138 pii: e20162940.
3. Karch D, Boltshauser E, Groß-Selbeck G, Pietz J, Schlack HG: Behandlungsverfahren bei Entwicklungsstörungen und zerebralen Bewegungsstörungen. Manualmedizinische Behandlung des KISS-Syndroms und Atlastherapie nach Arlen; Stellungnahme der Gesellschaft für Neuropädiatrie e. V. Manuelle Medizin 2005; 43: 100-5.

4. Flannery AM, Tamber MS, Mazzola C, et al.: Congress of neurological surgeons systematic review and evidence-based guidelines for the management of patients with positional plagiocephaly: executive smmary. Neurosurgery 2016; 79: 623-4.

5. Linz C, Schweitzer T, Brenner LC, Kunz F, Meyer-Marcotty P, Wermke $\mathrm{K}$ : Does shape affect function? Articulatory skills in babbling of infants with deformational plagiocephaly. Childs Nerv Syst 2017 (Epub ahead of print).

6. Wermke K, Linz C, Hasenberg A, Kunz F, Meyer-Marcotty P, Schweitzer $T$ : Six month-old infants with deformational plagiocephaly do not differ from unaffected infants with respect to vocal control. Intl J Ped Otorhinolaryng 2017; 102: 15-20.

Corresponding author:

PD Dr. med. Dr. med. dent. Christian Linz

Klinik und Poliklinik für Mund-, Kiefer- und Plastische Gesichtschirurgie

Universitätsklinikum Würzburg

Germany

Linz_c@ukw.de

PD Dr. med. Tilmann Schweitzer

Conflict of interest statement

The authors of all contributions declare that no conflict of interest exists.

\section{-O CLINICAL SNAPSHOT}

\section{Secondary Syphilis Without Any History of Primary Infection}

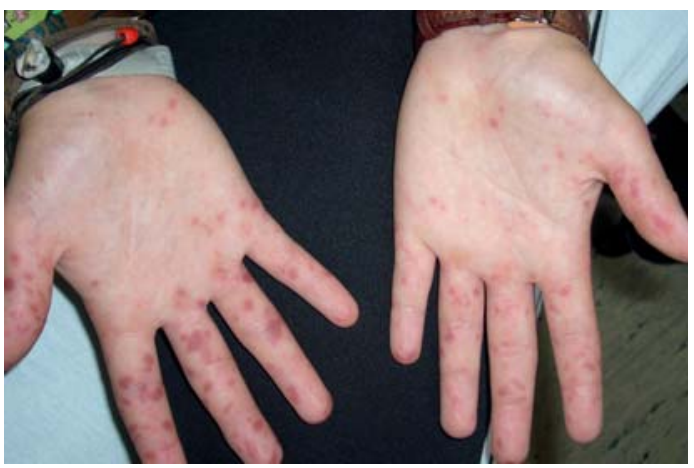

A 20-year-old male German student presented with a bilateral speckled rash, most prominent on the palms of the hands. He said the rash did not itch and was getting progressively worse. His family doctor, suspecting a contact allergy, had prescribed him a cortisone cream one week earlier, but this had not led to any discernible benefit. The patient had returned from a three-month stay in the Caribbean three weeks previously and had first become aware of the rash in his last few days there. The remainder of the physical examination was normal, including the mucous membranes and lymph nodes. Laboratory testing revealed a positive treponema pallidum hemagglutinin (TPH) test and a positive 19S-IgMFTA-ABS test, establishing the diagnosis of secondary syphilis despite the absence of any history of primary infection. This case underscores the importance of thorough history-taking, including a travel history.

Dr. med. Matthias Grade, Dr. med. Jan Bronnert, Zentrum für Infektiologie und Tropenmedizin, Christliches Krankenhaus Quakenbrück, m.grade@ckq-gmbh.de

Conflict of interest statement: The authors state that they have no conflict of interest.

Cite this as: Grade M, Bronnert J: Secondary syphilis without any history of primary infection. Dtsch Arztebl Int 2018; 115: 40. DOI: 10.3238/arztebl.2018.0040

Translated from the original German by Ethan Taub, M.D. 